\title{
Entrepreneurship and knowledge
}

\author{
Cristina Balaceanu, Professor, Ph.D \\ Faculty of Marketing \\ “Dimitrie Cantemir” Christian University \\ Diana Apostol, Assistant Professor, PhD \\ Faculty of Finance \\ "Dimitrie Cantemir” Christian University \\ Luminita Dragne, Assistant Professor, PhD \\ Faculty of Law \\ “Dimitrie Cantemir” Christian University
}

\begin{abstract}
This paper wants to propose a practical tool of working- as reliance for the process of abilities and entrepreneurial skills development- defined by flexibility, adaptibility, ease of use and quick response to business requirements requested. So, the purpose of this paper is to propose the development of an educational informatics platform which will be designed to acquire, develop and deepen the entrepreneurial knowledge, forming personal skills and behaviors applicable in all economic fields, from basic functions to the leading functions of any enterprise..
\end{abstract}

Key words: entreprenourship, decision, education, knowledge

JEL classification: I25, M54

\section{Introduction}

Entrepreneurship is the prerogative of the economic entrepreneur operating on the market under the market pulse, the forecasting opportunities of a particular market sector or the economy as a whole. Currently, the intensification of competition in the labor market, outsourcing production in economic fields that have greater comparative advantages in terms of production costs, increasing social costs caused by phenomena such as aging population, declining share of working age population in the total population, the increasing share of inactive persons arising from degradation of living standards and quality life appears - as a priority - the formation of entrepreneurial skills with an active role in the establishment and revenue assurance as a prerequisite for being.

\section{Innovations and entrepreneurship}

Innovating entrepreneurship is centered on acquiring specific innovation management research methods, human capital development and establishment of a business incubator, as support for the implementation of business ideas and entrepreneurial spirit.

The purpose of innovating entrepreneurship is to increase the competitiveness on the internal and external market of potential beneficiaries- technical- economic effects leading to increased productivity, 
accessibility to labor markets, increased interest in business and entrepreneurship idea. By applying the innovating entrepreneurship specific principles, it will be assured the evaluation and the development of the entrepreneur's economic performances.

In fact, the educational problem consists in the fact that that the educational market is non-functional, being in total absonant with the working market, which affects the quality of life and of the living standards. The educational system must stimulate the entrepreneurship and the innovation, encourage taking risks, the process of making decisions based on predictable or unpredictable risks, to develop incubators for the entrepreneurship stimulation and for the stimulation of responsiveness to agents in the socio-economic environment. Besides, in any society is essential to develop the educational system on educational levels to pursue vocational, skills-based, interests-based on each person fields aware of its value and usefulness while the time investment in education. At the same time, the economic environment will benefit by competitive, specialized, productive, flexible, dynamic workforce, leading to increase economic welfare, hence the quality of life.

The current knowledge stage of entrepreneurship is reflected in the low level of entrepreneurial development in Romania, revealed, among other things, by the reduced density of SMEs reported to the population, namely the value of 24 IMM-uri/1000 inhabitants below the average of 42 SMEs/1000 inhabitants of Europe. According to the study "Promoting entrepreneurship as a key factor for economic development" by Post-Privatization Foundation (October 2012) or GEM Global Report 2012 in Romania only 4\% of businesses are on their own (entrepreneurial), compared to 9\% in U.S., 8\% Latin America, 5\% in North Africa and Middle East, 13\% sub-Saharan Africa, 10\% in South Asia and Asia Pacific, European Union 7\%, 6\% non EU.

Currently, the educational road has a dominant theoretical character, which decreases the resilience of young graduate on labor market. As such, it requires a greater number of hours of practical training in specialized fields, participation in internships, volunteer programs aiming to develop entrepreneurial skills and abilities. Employers feel the need of an appropriate labor market tendency-based and economic specialization in and with practical specific skills for the activity field, generally being desirable to any employer a train graduate, both in terms of savings due to the reduction of hours of practical training during the probationary period, early-career and in terms of efficiency.

Entrepreneurship development bottlenecks are caused by socio-economic actual conditions that require the active involvement of workforce in programs and entrepreneurship activities to compete at the premises to obtain sufficient revenue growth to meet societal needs. Essentially, due to the proliferation of the current financial crisis, the employment is in a declining state pressure on the labor market which will be balanced by the combined effort of all economic actors: the state through policy measures to support entrepreneurship through specific levers, fiscal, monetary, population by realizing the necessity of entrepreneurship education, businesses, facilitating the access of entrepreneurs on labor markets in terms of fair, loyal competition.

The innovating entrepreneurship role is to discover what does not work in the economy and / or to solve economic problems by: change the system, dissemination solution, namely the determination of the company to identify and pursue new avenues of action. More specifically, the innovating entrepreneurship education aims to educate and to support entrepreneurial talent management to improve the management practices that will ensure 
a competitive business environment. In these conditions, future entrepreneurs will acquire skills enabling them to rationally use the financial, materials, energy, human and informative resources in line with market requirements, by the principles of sustainable development.

The innovating entrepreneur will appeal to the emotional intelligence to develop and to implement concepts that adapt to the individual needs, to improve its perception in relation to the needs of the community and the natural environment.

In highly measurement the emotional intelligence is an integrated, overall concept subsumed to the general concept of intelligence and designates the individual's ability to use emotions in a constructive, both for self-knowledge and knowledge transmission to others or the community in which he lives, in pursuit of action aimed at increasing personal and social welfare. One of the actions that highlight the benefits of emotional intelligence is the entrepreneurship. So, the entrepreneur builds constructive emotions suitable for the act of creation for its benefit and for the community's benefit, solving its problems in productive steps with economic character, attracting sympathizers and supporters. At the same time, the entrepreneur assumes leadership ambitions while his emotions regarding setting up a team, subtlety imposing entrepreneurial paths, make the general interest of the team's and community's needs.

Entrepreneur, known in the literature as an intrepid, is considered the central figure of the economy. Jean Baptiste Say consider the entrepreneur as the principal agent of economic progress, an industrial, active, educated man, ingenious inventor, inventive tiller, inventive businessman, bold man who gets involved in all in the extent that scientific discoveries are being made and the outlets expand. He is the one who, more than the normal capitalist, who gives money and collects royalties, more than a relatively passive landlord, more than a worker who receives orders on what he has to do, leads the production and distribution of wealth dominates. Thanks to the entrepreneur, shows Say, the value of the products is distributed among different productive services and various services are distributed across industries. In this way, the contractor transfers resources from an area with lower productivity in one with higher productivity and higher profit, creating therefore value.

Emotions are the foundation of communication and social relations. Therefore, the leader interested in emotionally capital growth is oriented towards the development of partnership relations with both employees and customers of its organization in order to develop affinities which, together, increase the chances of winning the organization through increased work motivation, facilitating communication, interpersonal development. Within the organization, leader's efficiency is the secondary result to its ability to generate and maintain constructive emotions such as confidence, interest, optimism, independence, enthusiasm that may cause effective behaviors that could be developed and used to solve problems, innovate products and services, improve service quality and customer relations, sustainable supports individual and organizational performances.

Through emotional intelligence, by unleashing constructive emotions, the leader or the entrepreneur can approach staff / team in order to capitalize on available resources effectively and increase the competitive advantage of the organization. To the extent that empathy creates value and utility of labor, leader will direct its own emotional states to creative, durable and equitable actions. 
From an entrepreneur's position it is a main condition to optimize the proportion costs-benefits. So, the inovative entrepreneur will develop those business oportunities that will increase his winning chances, without harming the comunity's sustainable development interests. Business, from this point of view, create development oportunities for the comunity, createworkplaces.

Any modern business, regardless of profile, size, ownership and socio-economic space in which it operates, requires a management style based on flexibility, dynamism and foresight, which is unthinkable without a complex, operative and quality information to underpin decision making. In order to increase the competitiveness of internal and external business it is necessary to improve information flows existing at the level of socio-economic structures and to provide methods to substantiate the business, and use information technology to innovate the field, given the strategies defined at European level.

In this context, innovative entrepreneurship comes in support for the business field, in an original and easily accessible way, giving information for an effective management and for an efficient organization of entrepreneurial activity, as a support of the development of a sustainable economy that respects the environment and involves precise inputs application in time and space. In the spirit of the above, the novelty of the innovative entrepreneurship lies in:

- creating an interface between $\mathrm{R} \& \mathrm{D}$ system and business environment, which provides tools and techniques for reliable work, easy to use and extremely useful for providing risk assessment, planning and managing control functions;

- providing information with higher quantitative and qualitative valencies, in terms of accuracy, reality, timeliness, response speed, form of presentation, completeness and information cost;

- "smart" decision making when wanted ("just-in-time"), which require a monitoring performance and a complete view of the business, in real time, updated and integrated information, modification and reorganization of any process;

- implementation of mathematical and social-economic analysis models in the system, which determine the possibility of choosing the optimal variant in the specific branch of activity and provide a more reasonable correlation with resource objectives;

- remove the anachronism of economic activity, anachronism manifested by the fact that most of the time is used for routine activities (such as accounting, data processing and reporting, etc.) and not for the work of specialized technical information, analysis and forecasting of economic phenomenons and processes that are of interest activity;

- substantiation of applications that provide all the economic information needed to increase competitiveness of a business by offering concrete alternatives and accurate response to the problems created in this activity.

\section{Conclusions}

The necessity to stimulate entrepreneurship policy starts from the need to develop the business environment by promoting and supporting innovative business ideas, with a favorable impact on the individual, community and environment. Through innovative entrepreneurship it is aimed to create a structure for implementing business using easy, modern, suitable tools to a contractor who knows the market and its development prospects. 


\section{Acknowledgement}

This work was supported by the European Social Fund through Sectoral Operational Programme Human Resources Development 2007 - 2013, project number POSDRU/159/1.5/S/134197, project title "Performance and Excellence in Doctoral and Postdoctoral Research in Economic Sciences Domain in Romania".

\section{References}

Baumgartner, S. and Quaas, M. 2010, Sustainability economics - general versus specific, and conceptual versus practical. University of Luneburg Working Paper Series in Economics, No.169, http://papers.ssrn.com/sol3/papers.cfm?abstract_id=1601202

Buckley, Casson, 1976, The future of the multinational enterprise, Macmillan, http://us.macmillan.com/thefutureofthemultinationalenterprise/PeterBuckley

Diana Hristache, Alina Creţu, 2001, Economic Doctrines, ASE Publishing House, Bucharest, Romania

\section{A. Marshall (1890), Principles of Economics, http://www.econlib.org/library/Marshall/marP.html}

Nedea Petronela-Sonia, Emilia PASCU, Milea Oana Maria, Pop Iuliana, 2013, Sustainable developement - a fundamental component in present and future social - economic - environment relationship, published in Natura Journal, vol 17, no 6, jun 2013, pp 44 - 51, ISSN: 0028-0631, Utrecht, Olanda, cotată Thomson Reuters - ISI, citată în BDI: Genamica, Elsevier Bibliographic, http://www.revistas-academicas.com/natura/search.html

Toman, M. A., Lile, R., and King D. (1998). Assessing Sustainability: Some Conceptual and Empirical Challenges. Resources for the Future Discussion, Paper 98-42, July, http://www.rff.org/rff/Documents/RFFDP-98-42.pdf 